\title{
PEIRCE, LACAN E A QUESTÃO DO SIGNO INDICIAL
}

Mauricio José d'Escragnolle Cardoso

Professor Adjunto do Departamento de Psicologia da UFPR. Membro do Laboratório de Psicanálise/UFPR. Colaborador do Grupo de Estudos Semióticos (Ges) USP). Doutor em Ciências da Linguagem, Université Paris X Nanterre.
RESUMO: Pouca atenção é dada, na literatura psicanalítica, às relações entre Lacan e Peirce. No entanto, a referência a Peirce é uma constante no ensino de Lacan a partir dos anos 1960. Por outro lado, a análise desta referência permite situar uma importante descontinuidade teórica no ensino de Lacan. Ela diz respeito a uma reforma importante da teoria do significante, cujo pivô é a introdução do conceito de signo. O artigo visa explicitar as diferenças teóricas entre Peirce e Lacan, assim como o uso particular que este faz de certos conceitos provenientes do pragmatismo.

Palavras-chave: Lacan, Peirce, pragmatismo, índex, objeto a.

ABSTRACT: Peirce, Lacan and the problem of the indexical sign. The relationship between Lacan and Peirce has not been given much consideration in the psychoanalytical bibliography. However, the reference to Peirce is a constant in Lacan's teachings from the sixties. On the other hand, the analysis of this reference permits us to situate an important theoretical discontinuity in his teachings. This discontinuity concerns an important modification in the theory of the signifier based on the introduction of the concept of sign. The article aims to explicit the theoretical differences between Peirce and Lacan and their particular use of some concepts coming from pragmatism.

Keywords: Lacan, Peirce, pragmatism, index, object a. 
C om respeito ao volume da literatura psicanalítica existente, pouco se consagra às relações entre as obras de Lacan e Peirce. No entanto, a referência a Peirce é uma constante no ensino de Lacan a partir de 1960. Esta referência é de suma importância para todos aqueles que visam compreender a evolução do pensamento lacaniano e desdobra-se ao menos em três tipos de questões.

Do ponto de vista crítico, permite situar uma descontinuidade teórica maior no interior da metapsicologia lacaniana. Esta descontinuidade localiza uma reforma importante na teoria do significante e cujo pivô é a introdução do conceito de signo. Se até o momento Lacan pensava ainda o excedente pulsional, agente no interior do sistema significante, a partir de uma teoria do objeto (por exemplo, inicialmente com a noção de fixação imaginária, e em seguida de objeto metonímico), nos anos 1960, inverterá sua démarche e buscará então definir a função objetal a partir de uma teoria do signo.

Do ponto de vista doutrinal, de diferentes interpretações acerca da questão do signo e do lugar que o pensamento peirciano ocupa na evolução de sua metapsicologia, podemos derivar diferentes interpretações do conjunto da obra de Lacan. Cabe aqui lembrar que uma orientação psicanalítica inteira se constrói na França em torno da tentativa de estabelecer uma hermenêutica doutrinal da obra lacaniana em torno de Peirce. Neste caso, busca-se substituir certos modelos lógicos ou linguísticos que foram mais ou menos influentes sobre a elaboração lacaniana — como de Saussure, Jakobson, Damourette \& Pichon ou Frege por uma interpretação exclusivamente peirciana. Seu maior expoente é Michel Balat, que há mais de 20 anos desenvolve uma leitura de Lacan inteiramente baseada na semiótica de Peirce.

Do ponto de vista especulativo, nos parece lícito considerar que a importância de Peirce para a elaboração lacaniana se refere ao Peirce logicista, e de forma alguma ao Peirce metafísico, já que o realismo peirciano, manifesto de forma exemplar em sua teoria do signo indicial, é incompatível com a perspectiva psicanalítica. Em outras palavras, as consequências metafísicas deste diálogo no interior da metapsicologia de Lacan não derivam da metafísica peirciana, mas, ao contrário, de sua exclusão, ou seja, do privilégio acordado por Lacan à face exclusivamente logicista do pragmaticismo.

Assim, não se trataria de simplesmente substituir a influência de certos autores referidos por Lacan pelo pragmaticismo lógico de Peirce. Consideramos mais interessante buscar a justa medida da presença de Peirce no interior da evolução do pensamento lacaniano, explicitando, por um lado, as diferenças epistêmicas entre os dois autores e, por outro, o tratamento que Lacan imporá aos conceitos peircianos. Desta maneira, veremos que a exlusão da metafísica peirciana permite a Lacan um tratamento inteiramente metapsicológico da questão do índice e, 
depurando-o de toda leitura realista, dá origem a um importante instrumento nocional para a sua reflexão sobre o gozo.

\section{PEIRCE E A QUESTÃO DO ÍNDICE}

Quando Lacan introduz o conceito de signo em seu seminário sobre a ética da psicanálise, durante a lição de 13 janeiro de 1960, seu quadro de referência é o conceito peirciano de índice. Para podermos compreender a interpretação lacaniana deste conceito, comecemos pela definição que Peirce fornece:

“[Um índice é] um signo ou uma representação que reenvia a seu objeto não tanto porque possui alguma similaridade ou analogia com ele, nem porque está associado com as características gerais que este objeto possui , mas porque está em conexão dinâmica (aí compreendida espacial) com o objeto individual de um lado e com os sentidos e a memória da pessoa para quem serve de signo, por outro lado." (PEIRCE, 1931-1958, § 2.305)

Assim,

“Os índices podem se distinguir dos outros signos ou representações por três características: primeiramente, não possuem nenhuma semelhança significativa com seus objetos; em segundo lugar, reenviam a indivíduos, unidades singulares, a coleções singulares de unidades, ou a contínuos singulares; em terceiro lugar, dirigem a atenção sobre seus objetos por impulsão cega.” (idem, § 2.306)

E, então,

“Um índice é um signo que perderia imediatamente o caráter que faz dele um signo se seu objeto fosse suprimido, mas não perderia este caráter se não tivesse um interpretante. Exemplo: um molde com um buraco de bala dentro como signo de um tiro; pois sem o tiro não haveria furo; mas há um furo aí, quer alguém tenha a ideia de atribuí-lo a um tiro ou não.” (idem, § 2.304)

Um índice reenvia a seu objeto se é afetado por este objeto, se se inscreve em uma relação causal com seu objeto. Enquanto tal, o índice responde, no interior do registro semiótico que lhe é próprio, à categoria peirciana da Secundidade. Esta categoria relaciona-se à realidade enquanto composta de "fatos brutos" e, logo, a um tipo de existência depurada de todo pensamento e que Peirce chama de "faticidade do concreto" (idem, § 1.324). Esta dimensão da realidade e da causalidade mecânica não possui nenhum espaço para a indeterminação: a Secundidade 
pressupõe em sua definição "uma necessidade incondicional, i.e. força sem lei nem razão, força bruta” (idem, § 1.427). É por causa desta crença na brutalidade de uma realidade anterior à semiosis que "a semiótica peirciana é indissociável do realismo ontológico propriamente dito” (TIERCELIN, 1993, p.194). Com efeito, a postulação do índice como fato primitivo na teoria dos signos manifesta de maneira explícita esta dimensão realista da semiótica peirciana.

Como observa Peirce, reconduzido à relação físico-causal que une o signo e o objeto, o índice é o tipo de signo que menos necessita de um interpretante. O interpretante é assim exterior a esta relação física que une o índice ao seu objeto. Ainda mais, para Peirce, o índice, quando se manifesta, interpela o sujeito, que não pode então permanecer indiferente a esta ocorrência. Peirce fornece como exemplo uma 'batida na porta', um dedo apontando um objeto ou um fenômeno natural como um trovão, os quais apresentariam a particularidade de interpelarem diretamente o sujeito (PEIRCE, 1931-1958, § 2.285 e 2.286). Com respeito a este último exemplo, que Peirce nos forneça um fenômeno desde sempre associado à experiência do sublime, pode parecer — à primeira vista corresponder perfeitamente à definição lacaniana do signo enquanto índice da Coisa. Assim, o índice "chama a atenção”, ele "surpreende” o indivíduo, servindo como conexão entre duas experiências distintas (idem, § 2.285).

Mesmo se designa o caráter concreto de uma experiência que lhe serve de princípio causal, o índice não fornece necessariamente uma indicação exata e precisa sobre sua própria origem. O índice pode, assim, designar uma causa indeterminada. O índice é, então, um fato que se oferece de imediato à percepção, indicando uma origem causal que pode, quanto a ela, não ser oferecida à experiência. De toda maneira, sua ocorrência convida o interpretante a remontar da percepção do efeito (o representâmen) à sua fonte causal, o objeto. Enquanto portador de uma função, em essência, referencial e cognitiva, o índice denota um acontecimento situado no tempo e no espaço. Fazendo isso, ele é sempre correlato a um registro contextual. Assim, a função cognitivo-referencial do índice implica sempre a afirmação da existência de seu objeto e a necessidade de um conhecimento prévio, da parte do interpretante, acerca dele. Segundo Peirce:

\footnotetext{
“Um signo, ou representâmen, é alguma coisa que ocupa o lugar para alguém de alguma coisa, sob alguma relação ou a algum título. Ele se endereça a alguém, isto é, cria no espírito desta pessoa um signo equivalente ou talvez um signo mais desenvolvido. Este signo que ele cria, eu o chamo o interpretante do primeiro signo. Este signo ocupa o lugar de alguma coisa: de seu objeto. Ele ocupa o lugar desta coisa, não em todos os seus aspectos, mas com respeito a uma sorte de ideia que eu algumas vezes chamei o fundamento do representâmen.” (1931-1958, § 2.228)
} 


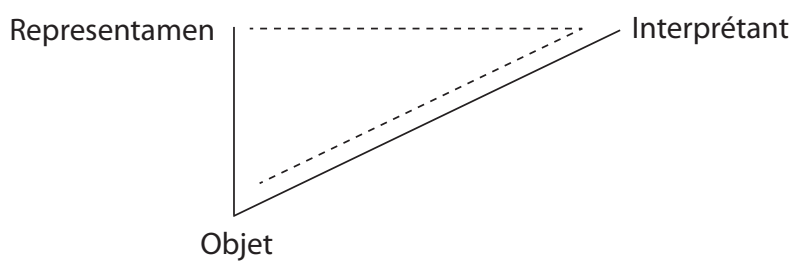

A relação existente entre o objeto designado e o conhecimento prévio ou colateral requerido ao sujeito constitui um ponto fundamental para o emprego do índice. Mesmo em sua relação indicial ao objeto, o índice apresenta sempre certo grau de incerteza semântica que o conhecimento prévio do sujeito tenta compensar. Como no caso de outros tipos de signo, o índice peirciano implica uma margem de indeterminação do sentido que força o desdobramento contínuo da atividade semiótica. A questão do vago — inerente à atividade semiótica — é assim um componente central da investigação peirciana.

Peirce considera que o vago é um componente próprio à comunicação. Segundo Chauviré, o vago "afeta os enunciados de um diálogo no qual cada um dos dois participantes sabe (ou pressupõe) que o outro conhece tudo isto que é necessário para compreender o que ele diz; se trata então de um vago reduzido pelo conhecimento do contexto linguístico e extralinguístico" (CHAUVIRÉ, 1995, p.18).

O vago está sempre referido à existência de indivíduos precisos e envolve, sobretudo, a impossibilidade de determinar as condições de verdade de uma ocorrência ou proposição. Seu correlato é justo o conhecimento prévio ou colateral, não apenas no sujeito interpretante, mas também como saber suposto no outro envolvido na troca comunicativa.

É desta correlação entre determinação do objeto e condição de verdade que provém a distinção peirciana entre objeto imediato e objeto dinâmico. O objeto é sempre um objeto de pensamento, mas ele pode ser analisado segundo dois aspectos diferentes. O objeto dinâmico é o objeto tal como ele existe na realidade, enquanto objeto externo (chamado também por Peirce de um segundo dinâmico) que precipita o início do processo interpretativo. O objeto imediato seria, por sua vez, o objeto tal como o índice o representa, ou seja, a forma simbólica construída quando buscamos apreender o objeto dinâmico. No entanto, o índice não reenvia ao objeto em todos os seus aspectos. Este reenvio semiótico, o processo representacional de fato, é determinado por isto que Peirce chama de fundamento (ground): o aspecto particular a partir do qual o signo reenvia ao seu objeto. O objeto imediato é, assim, contrariamente ao objeto dinâmico, um objeto pensado, e, logo, de origem hermenêutica. O processo semiótico implica, do fato de seu potencial infinito de desdobramento, que estes dois tipos de 
objetos jamais coincidam. Este deslocamento constitutivo entre o objeto imediato e o objeto dinâmico pode ser entendido como o fundamento mesmo do vago (e que exige então a recursividade do processo semiótico).

\section{A INADEQUAÇÃO DA SEMIÓTICA PEIRCIANA PARA A ORIENTAÇÃO LACANIANA}

Como dissemos, é de Peirce que Lacan toma emprestado o conceito do signo quando ele o emprega no seminário da Ética. Mas, a transformação que Lacan faz sofrer ao conceito peirciano faz com que esta filiação se torne quase que somente nominal. Todos os pressupostos, todos os elementos teóricos utilizados no início pelo filósofo americano são interpretados segundo uma perspectivaestrangeira a Peirce. Vejamos alguns exemplos da inadequação da perspectiva peirciana com respeito ao campo psicanalítico, que força esta interpretação radical por parte de Lacan:

\section{A questão do vago}

A noção de vago possui, em Peirce, um estatuto eminentemente epistemológico e cognitivo em sua essência, e, logo, secundariamente ontológico. O objeto determina o signo-representâmen de modo causal, a partir do fundamento, que, por sua vez, especifica a visada a partir da qual o objeto imediato pode se apresentar fato semiótico que implica o caráter sempre parcial da interpretação. Com isso, o objeto dinâmico é, por força, semanticamente mais rico que o objeto imediato. O vago semiótico resulta então dos próprios limites intrínsecos da função de mediação que o representâmen exerce entre interpretante e objeto.

Assim sendo, podemos perceber um duplo aspecto relativo ao realismo peirciano. De um lado, mesmo se o objeto dinâmico deva ser considerado como a visada do processo semiótico (um pressuposto semiótico), ele precisa ser postulado como um existente real independente. Como afirma Chauviré, "o índice exige e garante, segundo Peirce, a presença, ou ao menos a existência de seu objeto, senão no contexto da enunciação, ao menos em um universo já identificado" (1995, p.70). De outro lado, este objeto dinâmico sustenta o processo semiótico de maneira causal, determinando assim por inteiro o signo que o representa. O índice-representâmen é então o signo que entretêm uma relação dinâmicocausal com um objeto prévio, ambos inteiramente determinados. Como observa Peirce em uma carta à Lady Welby, "a indeterminação pertence somente às ideias; o existente é determinado inteiramente; e é justamente nisto que consiste a causalidade" (PEIRCE, 1978, p.27). A indeterminação apenas participa semioticamente do lado do interpretante e jamais do lado da relação índice-objeto. 
A consequência da introdução da causalidade no interior do processo semiótico é que mesmo se a linguagem pode ainda ser considerada como constitutiva do pensamento, ela possui, em última instância, um estatuto somente secundário com respeito ao objeto e à realidade. Peirce considera assim a linguagem, ao menos no que concerne à determinação indicial do objeto, como um instrumento de mediação. A teoria peirciana implica de fato uma dupla redução: da linguagem ao estatuto de mediação e, em segundo lugar, do real ao papel de substrato pré-simbólico (PEIRCE, 1931-1958, § 2.92).

Esta característica realista se manifesta mesmo se consideramos que, para Peirce, toda forma de existência para um sujeito é desde sempre determinada de maneira semiótica. Neste caso, podemos considerar que tanto o objeto quanto o representâmen são desde sempre signos potenciais, ou, mesmo, extrapolando, que toda a realidade pode, a partir de certo momento, começar a funcionar semioticamente. Sem dúvida, para Peirce, não podemos nunca ter acesso a uma existência extrassimbólica. Entretanto, ao contrário de Lacan, para a semiótica peirciana o próprio conceito de signo é modelado sobre uma noção extrassemiótica e, mais precisamente, a partir de uma concepção empirista de objeto. Não é outra coisa que nos ensina a importância do conhecimento prévio ou colateral no interior do processo semiótico.

\section{Empirismo e hábito}

A clivagem ontológica, em Peirce, não se inscreve então entre a representação subjetiva (intuitiva e espontânea) e a estrutura da linguagem/realidade, mas entre o pensamento/linguagem e a realidade. É por esta razão que quando Peirce tenta determinar o que poderia encenar o papel de interpretante último que fecharia, mesmo que momentaneamente, o processo semiótico, ele o concebe sob a forma do hábito. Dito de outra maneira, a situação semiológica ideal é aquela na qual a relação entre o interpretante e o representâmen repete a relação entre o representâmen e o objeto. No caso do índice, é a própria relação causal que seria repetida entre o representâmen e o interpretante. Com efeito, a definição pragmática do hábito considera que a plena significação de um termo só pode ser apreendida por meio de seu emprego e das consequências de seu uso, ou seja, pelas modificações que esta ocorrência acarreta. Por ser o pragmatismo peirciano (e, talvez, todo e qualquer pragmatismo) fundamentalmente realista, o acento teórico será posto sobre o poder de determinação que a regra exerce sobre o comportamento, e de nenhuma maneira sobre a natureza - ela mesma inconsistente da regra. Dito de outra maneira, para Peirce, é esta transposição da causalidade sobre a relação entre representâmen e interpretante que funda o hábito (e a regra que o determina). 
“Assim, do ponto de vista pragmatista, quando o processo semiótico atinge seu interpretante lógico último, ele encontra enfim sua 'verdade'; pois isto a que 'aspiram' os signos e as significações, é governar a conduta e os atos: 'a significação de uma palavra' têm por propriedade 'tender a modelar a conduta de uma pessoa' (...)” (CHAUVIRÉ, 1995, p.81)

Esta maneira de conceber o hábito, como a consequência de um constrangimento causal sobre a ação, é fruto direto do fundamento empirista do pragmatismo de Peirce. Com efeito, Peirce demonstra que é necessário, em primeiro lugar, já ter-se adotado uma perspectiva causalista sobre o processo semiótico, para que, em seguida, seja possível definir o hábito a partir do poder de determinação da ação. Assim, concernindo os laços unindo pensamento e realidade, apesar de sua postura antipsicologista, Peirce permanece prisioneiro de uma teoria empirista da representação. Ele busca elaborar um modelo semiótico no qual a efetividade "não deriva de nenhuma maneira da razão, como a força muscular do braço do policial ou do oficial de justiça, mesmo se ele obedece à razão, assim como um cão não é menos um bruto quando ele obedece a seu mestre, que o adestrou pela força do hábito, ou mesmo através de meios mais brutais" (PEIRCE, 1978, p.37).

Vemos que uma concepção realista está assim no fundamento da semiótica peirciana.

\section{Ostensão e conhecimento prévio ou colateral}

Observamos assim que Peirce parte sempre da realidade e a entrevê como modelo da determinação da função do índice. Com respeito a isso, seu modelo de um autêntico índice é o índice não linguístico, do qual o caso exemplar é o dedo apontado na direção do objeto.

Da mesma maneira, Peirce considera o olhar e a voz como protótipos da função indicial. Neste caso, suas funções não são apenas de ostensão, mas também de definir o universo do discurso e, em particular, determinantes na distinção entre ficção e realidade. Para Peirce, a voz e o olhar são índices na medida em que conduzem a atenção do interlocutor na direção da realidade à qual se refere o discurso e designam um existente com menos incerteza que um símbolo. Assim, segundo o filósofo americano, o índice possui duas características diferentes, mas imbricadas. Em primeiro lugar, de instituir uma relação direta-causal. Em segundo lugar, de interpelar o interpretante de um ponto de vista pragmático, ao reproduzir a relação causal do índice ao objeto sobre o interpretante ele-mesmo.

Vemos que a semiótica peirciana induz então a uma forma de naturalização do processo indicial. Ou seja, ao passo que ela põe o acento teórico sobre a realidade, o uso de índices requer a existência de um 'conhecimento colateral' 
relativo ao objeto designado. É necessário que o sujeito seja possuidor de um conhecimento colateral para que ele possa reconhecer o referente do índice. Este conhecimento colateral forma assim um conhecimento prévio da relação causal em jogo, no que ela é pertinente para a determinação do objeto no interior da associação semiótica. Sublinhemos com precisão: o conhecimento prévio ou colateral é concebido, por Peirce, sobre o modelo da experiência sensível. A questão do conhecimento colateral só pode ser pertinente, de maneira precisa, em um universo semiótico no qual a função maior do signo é a ostensão. Em outras palavras, a importância do conhecimento colateral é o correlato direto de uma caracterização não-hermenêutica do signo. Como observa Chauviré, "o papel do signo se vê limitado ao aporte de um suplemento de informação sobre objetos já conhecidos de outra maneira. A eficacidade do índice é então subordinada a esta condição: o intérprete deve ter uma experiência colateral do objeto" (1995, p.137).

Segundo Peirce, o exemplo mais significativo desta exigência de conhecimento colateral é dado pelo caso do nome próprio. Para Peirce, “um nome próprio somente pode funcionar como tal, se o enunciador e o intérprete são mais ou menos familiarizados (acquainted) com o objeto que ele nomeia" (CHAUVIRÉ, 1995, p.260). Com efeito, o nome próprio, por definição, em Peirce, exige que duas condições de aplicação pragmática sejam respeitadas. Em primeiro lugar, que o objeto que porta o nome seja um indivíduo singular. Em seguida — sendo este o ponto heuristicamente mais delicado - que o intérprete já tenha uma familiaridade com o objeto do ponto de vista de uma experiência cognitiva concreta anterior (PEIRCE, 1931-1958, § 2.329). Desta maneira, desde a primeira ocorrência deste índice que é o nome próprio, o conhecimento colateral — de caráter extra-semiótico em essência — deve já estar presente, pois, caso contrário, o interpretante correria o risco de não reconhecer a relação semiótica existente entre o representâmen e o objeto, o que implicaria simplesmente o fracasso do processo semiótico.

\section{CONCLUSÃO: TRATAR DE MODO METAPSICOLÓGICO O SIGNO INDICIAL PEIRCIANO É JUSTO FAZÊ-LO DEIXAR DE SER PEIRCIANO}

Tomemos como referência o seminário sobre a ética da psicanálise, de 1959/1960. Para Lacan, refletir sobre a questão ética a partir da psicanálise significa um “aprofundamento desta noção de real e, [...], é na medida em que se trata de uma orientação da baliza do homem com respeito ao real que a questão ética se orienta e se articula” (LACAN, 1959/1960, p.23). O real será tematizado como isto que constitui um ponto de referência, o signo a partir do qual a economia psíquica se orienta. O passo de Lacan será justo de despojar a teoria peirciana do índice 
de seus princípios empiristas para este fim. Podemos mesmo dizer que ele fará o índice peirciano sofrer um tratamento metapsicológico de fato. Esta interpretação do conceito é julgada necessária por Lacan para que o conceito de signo indicial (e, na sequência de sua reflexão, o conceito de nome próprio) seja capaz de dar conta da imbricação da ordem significante com o registro pulsional.

Este laço entre a satisfação da pulsão e a dimensão simbólica constitui o ponto pivô da formação da realidade. Neste domínio, a ficção não é oposta à realidade, pois esta imbricação é constitutiva. O que se opõe à ficção (se não é a realidade)? Para a psicanálise, trata-se da inércia da excitação pulsional. Esta inércia pulsional indica a presença da Coisa e funciona, com referência ao psiquismo, como um signo.

"Que o inconsciente seja estruturado em função do simbólico, que isto que o princípio do prazer faça o homem buscar, seja o retorno de alguma coisa que é um signo, [...], eis aí o que é necessário medir toda a importância no pensamento freudiano para então podermos também conceber qual é, então, a função, o papel da realidade.” (LACAN, 1959/1960, p.25)

Este retorno que é signo para o psiquismo não é outra coisa senão o modo de manifestação da afetação pulsional. Aqui, cabe precisar que esta excitação pulsional pode retornar como signo justo uma vez que ela foi antes externalizada, rejeitada pelo psiquismo, e que nesta expulsão (fruto do julgamento primário de atribuição) um afora propriamente dito é constituído. Esta "coisa que faz signo" (LACAN, 1959/1960, p.85) é assim a manifestação de Das Ding, da qual Freud nos fala no Projeto de 1895: o resto constante e incompreensível de todo complexo perceptivo do sujeito. Ela é este objeto extranho que a atividade judiciativa constitui a partir "disto que do interior do sujeito se encontra originalmente conduzido para um primeiro afora” (idem, p.87).

“A noção deste Ding, deste Ding como fremde, como estrangeiro e mesmo hostil, em todo caso como o primeiro exterior, eis aí em torno do que se orienta todo o percurso que, sem nenhuma dúvida, para o sujeito, é a todo instante percurso de controle, percurso de referência, com respeito a quê? Ao mundo de seus desejos." (idem, p.88)

A partir desta reflexão, Lacan considera que noções econômicas, como as de fixação ou sublimação, estão na base de problemas metapsicológicos que podem ser repensados a partir de uma teoria do signo que seja conforme à lógica do significante. Com efeito, Lacan deixa entrever a possibilidade de uma teoria 
metapsicológica do signo referente a “das Ding, isto é, o lugar de seu desejo, seja ele perverso ou sublimado” (idem, p.166).

É no sentido de pôr em relevo os paradoxos econômicos implicados nas noções de fixação (da pulsão parcial no objeto pré-genital), de sublimação, assim como de outros fenômenos associados à dimensão econômica do aparelho (como a angústia, o amor cortês, a reação terapêutica negativa, etc.) que Lacan emprega pela primeira vez a fórmula, emprestada de Peirce, do signo: “o signo, é aquilo que está no lugar de alguma coisa para alguém” (idem, p.141).

O emprego da noção de signo permite a Lacan demonstrar que tanto a sublimação quanto a fixação são paradoxalmente variações de um mesmo processo econômico. Nos dois casos, se trata do que diferencia, em essência, uma pulsão de um energetismo natural, ou seja, do que faz da pulsão uma função simbólica por completo. Um signo será, neste caso, a exteriorização reificada da exigência pulsional, isto é, a constituição de uma forma objetal primária. Este processo de reificação que constitui o signo dá origem a uma forma de positividade que, de modo paradoxal, decorre apenas de um sistema significante de diferenças. Esta positividade não é nada mais que a forma própria de manifestação da indeterminação inerente à ordem da linguagem. De maneira mais exata, a substancialização (a reificação) de um limite simbólico.

Segundo esta perspectiva, o vago deverá ser considerado, sobretudo, do ponto de vista ontológico e não, como em Peirce, sob o ângulo epistemológico e cognitivo. O registro do simbólico é inconsistente e, de fato, a própria determinação semiótica implica nela mesma a indeterminação: o signo é uma forma específica de determinação da indeterminação. Mas, sobretudo, a ordem simbólica sendo considerada como constitutiva da realidade, a indeterminação se torna uma fratura ontológica positiva. Ao contrário da concepção de Peirce, o signo na psicanálise encarna a inconsistência da ordem simbólica, e de maneira alguma uma simples limitação cognitiva relativa ao caráter parcial de toda interpretação. Em outras palavras, não se trata de uma limitação da linguagem entendida como instrumento de mediação, mas da natureza ontologicamente contraditória da própria determinação do real.

Por certo, uma das características do signo, em Lacan, é também, tanto como em Peirce, sua ausência de equivocação. Todos nós conhecemos a máxima, citada antes, segundo a qual "um signo é aquilo que representa alguma coisa para alguém”. No entanto, talvez seja mais correto considerarmos que o signo apresenta — no sentido de uma mostração — e não 'representa' alguma coisa. Mas, mesmo neste caso, a designação do signo não será outra coisa que a própria indeterminação. Assim, o signo não designa uma indeterminação, ele é a determinação enquanto tal da indeterminação. O signo definido do ponto de vista da metapsicologia dá origem a um conceito reflexivo, e de forma alguma permite endossar uma 
perspectiva dualista-realista. No caso da metapsicologia lacaniana, o conceito de signo estará na base da noção — desenvolvida mais tarde por Lacan em torno do Seminário XIX — de Um: a única forma de positividade imanente ao registro do significante, a insistência da mesmidade.

Esta redefinição do conceito peirciano de signo pode ser posta em relevo a partir dos exemplos da voz e do olhar. Ao contrário de Peirce, a voz e o olhar implicam, para a psicanálise, a presença de um abismo semântico, isto é, de um elemento que existe apenas enquanto impasse da simbolização. A ausência de equivocidade concerne neste caso ao caráter pertubador ou sedutor do signo indicial em função do sem-sentido que ele implica (e que, no caso da psicanálise, assume um valor de gozo).

Observamos assim que essa maneira de conceber o conceito de signo em Lacan implica necessariamente a exclusão de toda forma de determinação causal da relação semiótica entre o representâmen e seu objeto. Percebemos aí uma das características maiores da releitura lacaniana do signo. Mesmo se assistimos a uma forma de reintrodução do referente com a noção de signo, este referente metapsicológico não é outra coisa senão o próprio limite interno da simbolicidade. A 'substância' denotada pelo signo não é mais que a própria inconsistência interna ao universo da linguagem e, logo, de maneira alguma, um subsistente extra ou pré-simbólico.

O signo é, assim, a manifestação, no interior do campo do sensível, da imaterialidade própria aos valores simbólicos e, nesse sentido, de um valor puro. Ele é a apresentação do limite intrínseco e reflexivo da ordem simbólica. É por essa razão que Lacan assenta, enfim, sua interpretação do signo peirciano a partir da teoria do objeto a: "O que é que se deve substituir, no esquema de Peirce, para que ele cole com minha articulação do discurso analítico? É simples como dizer bom-dia, [...], não há outro representâmen senão o objeto a” (LACAN, 1971/1972a, p.179).

Lacan desloca assim o lugar do objeto, em Peirce, para aquele relativo ao representâmen (ao signo indicial). Efetivamente, o fato de assimilar o conceito de representâmen ao de objeto a induz a uma modificação radical da teoria do signo. A teoria peirciana do índice pode assim ser útil para teoria psicanalítica à condição de sofrer uma releitura estrutural.

Segundo esta interpretação de Lacan, o objeto dinâmico peirciano, por sua vez, não será mais um objeto extrassimbólico que exerce uma função causal sobre o signo indicial, mas apenas um pressuposto intuitivo. Ele tomará justamente o lugar da Coisa, ou seja, de uma ideia reguladora que opera como um pressuposto da própria atividade simbólica. Desde que nós estamos implicados em uma atividade semiótica e que o objeto a exerce sua função de signo para alguém, o efeito é a pressuposição da Coisa. Em outras palavras, se o signo-representâmen 
ocupa o lugar da reificação de uma inconsistência (ou seja, sob a forma de objeto a), a Coisa é a manifestação de seu pressuposto pragmático. Neste caso, a Coisa deixa de ser a causa primeira do representâmen-objeto a, mas, ao contrário, passa a ser seu efeito. O representâmen-objeto a deixa de ser também um existente empírico em uma relação (sêmio) causal com um outro objeto de mesma natureza (entre dois objetos homogêneos), e se torna simplesmente - para empregar uma expressão de Zizek — um efeito de paralaxe (ZIZEK, 2008, p.23).

Que nos demonstraria então esta teoria metapsicológica do signo? Lacan o afirma com clareza: "o discurso em sua relação, [...], ao nada. Isso quer dizer este em torno do que necessariamente gira todo discurso" (LACAN, 1971/1972a, p.178). O signo não 'representa' - como uma espécie de etiqueta colada sobre uma coisa -, ele é o nada inerente à ordem simbólica que, de súbito, se 'mostra' no interior do campo da experiência. Como diz Lacan, este signo designa o fato que "a ontologia é simplesmente, [...] a careta do Um" (LACAN, 1971/1972a, p.169). Dito de outra maneira, o signo é o Um simbólico que marca a presença do irrepresentável no seio da representação, não como forma qualitativamente sensível ela-mesma, mas como exigência de simbolização ou de captação de gozo. Ou seja, um Signo é aquilo escreve Um gozo para alguém.

Por último, podemos ver que uma maneira lacaniana de conceber a questão da regra e do hábito também se torna diferente da formulação peirciana. Peirce considera, como vimos, a conduta como a manifestação concreta do hábito (a manifestação da força da regra). Lacan, ao invés de naturalizar a normatividade da regra, vai se interessar pela origem do apego de um sujeito a uma regra qualquer (como no caso do velho problema sociológico da servidão voluntária). Para a psicanálise, a regra, a lei (simbólica), ou não importa qual outra função simbólica, não possui força determinante enquanto tal e não responde a um modelo causal. Seria, assim, sobre a inconsistência da regra que o acento teórico seria posto, como o equivalente do lugar do consentimento do sujeito.

Para terminarmos, cabe ressaltar que, numa perspectiva lacaniana, o hábito deve ser considerado a resultante de um sistema que se caracteriza pela ausência de fundamento natural. Isto é, somente haveria costume, hábito, convenção, quando a determinação causal estivesse suspensa. O estatuto de hábito de uma prática simbólica repousaria então sobre o caráter insensato da ordem da linguagem e sobre o gozo aí envolvido para um sujeito qualquer. Temas estes, em última instância, não apenas estranhos ao pensamento de Peirce, mas impossíveis de nele serem corretamente abordados.

Recebido em 16/7/2009. Aprovado em 16/3/2010. 


\section{REFERÊNCIAS}

CHAUVIRÉ, C. (1995) Peirce et la signification. Paris: PUF.

ECO, U. (1976) Peirce's Notion of Interpretant. MLN, v.91, n.6, Comparative Literature, p.1.457-1.472.

HOOKWAY, C. J. (Ed.) (2006). The Cambridge companion to Peirce. New York: Cambridge University Press.

LACAN, J. (1959-1960) Le Séminaire - livre VII - L’Éthique de la psychanalyse. Version AFI.

. (1971-1972a) Le Séminaire - Livre XIX - Ou Pire. Version AFI.

(1971-1972b) Le Séminaire - Livre XIX B - Le Savoir de l’Analyste.

Version AFI.

PEIRCE, C.S. (1931-1958) The Collected Papers of Charles Sanders Peirce. 8 v. Cambridge: Harvard University Press.

\section{Seuil.} . (1978) Écrits sur le signe. DELEDALLE, Gérard (Org). Paris:

(1987) Textes Fondamentaux de Sémiotique. Foz, Clara. FouchierAxelsen, Berthe. (Dir). Paris: Klincksieck.

. (2002) Pragmatisme et Pragmaticisme. Euvres I. Sous la direction de Claudine Tiercelin et Pierre Thibaut. Paris: Éditions du Cerf.

SOUBBOTNIK, M. (2001) La philosophie des actes de langage: la doublure mentale et l'ordinaire des langues. Paris: PUF.

TIERCELIN, C. (1993) La pensée-signe - Études sur C.S. Peirce. Nîmes: Éditions Jacqueline Chambon.

ZIZEK, S. (2008) La Parallaxe. Paris: Fayard.

Mauricio José d'Escragnolle Cardoso

escragnolle@hotmail.com 